\title{
Association between personality type, affective distress profile and quality of life in patients with psoriasis vs. patients with cardiovascular disease
}

\author{
ELENA PORUMB-ANDRESE ${ }^{1,2}$, DAN VÂȚĂ $\breve{~}^{1,2}$, ROXANA POSTOLICĂ $\breve{~}^{3}$, LAURA STĂTESCU $^{1,2}$, \\ CRISTIAN STĂTESCU ${ }^{4}$, ALINA-IOANA GRĂJDEANU ${ }^{1}$, ADRIANA IONELA PĂTRAȘCU ${ }^{2}$, \\ IOANA ADRIANA POPESCU ${ }^{1}$ and LAURA GHEUCĂ SOLOVASTRU ${ }^{1,2}$
}

\author{
${ }^{1}$ Department of Dermatology, University of Medicine and Pharmacy 'Gr. T. Popa', 700115 Iași; ${ }^{2}$ Dermatology Clinic \\ of The Clinical Emergency County Hospital ‘Sf. Spiridon’, 700111 Iași; ${ }^{3}$ Regional Institute of Oncology, 700483 Iași; \\ ${ }^{4}$ Cardiology Clinic of The Institute of Cardiovascular Diseases, 700503 Iași, Romania
}

Received April 22, 2019; Accepted July 23, 2019

DOI: $10.3892 / \mathrm{etm} .2019 .7933$

\begin{abstract}
Common chronic conditions, such as cardiovascular diseases and psoriasis, are associated with increased psychological distress. Health-related quality of life and personality type in patients with these two diseases were evaluated, including the patient's ability to respond truthfully or his/her tendency to be introverted or extroverted. The subjects $(n=63)$ responded to questionnaires including: SF-36 questionnaire, Eysenck test and the questionnaire of the affective distress profile designed to assess the subjective dimension of functional negative emotions, dysfunctional negative emotions and positive emotions. Psoriasis patients had significantly higher average scores of physical functions and limitations brought on by emotional problems. Emotional instability was common for both types of patients and anxiety was associated with a low level of education. Overall, we believe that it is necessary to include items evaluating the patients' affective profile and personality in the assessment protocols of these diseases. These items could help the clinician in identifying possible factors that signal worsening of the disease or of non-response to treatment.
\end{abstract}

\section{Introduction}

Human personality and its connections to various somatic disorders represents a research subject that has recently been drawing attention and is a reoccurring theme in many clinical trials. The skin is closely related to the mind and is

Correspondence to: Mr. Dan Vâță, Department of Dermatology, University of Medicine and Pharmacy 'Gr. T. Popa', 16 University Street, 700115 Iași, Romania

E-mail: danvata@yahoo.com

Key words: psoriasis, cardiovascular diseases, quality of life, personality, affective distress profile considered as the 'organ of expression' of the human body. However, this correlation can be thought of in a different way as well; through its visibility, any major lesion from the skin can bring emotional, psychological and/or social changes. We mention the association between anxiety or depression and acne vulgaris, psoriasis or bullous pemphigoid $(1,2)$, the link between lifestyle factors and atopic dermatitis (3) or the association between stress hormones and cutaneous pathophysiological processes, such as melanoma (4-6). In addition, at molecular level, high levels of oxidative stress parameters were found in psoriasis (7).

Thus, a new concept, psychodermatology, is a concept that focuses on the diagnosis and treatment of psychiatric disorders associated with cutaneous manifestations, as well as combating social isolation associated with such disorders (8).

Health is defined as the state of complete physical, mental and social well-being, not just the absence of disease or infirmity (World Health Organization 2006, www.who.int). Thus, health is linked to the quality of life and is referred to as 'health-related quality of life (HRQL)'. It is an increasingly common term used in clinical practice to assess the impact of various illnesses on patients' quality of life.

According to the American Psychiatric Association (www. psychiatry.org), personality disorders define those types of mental disorders in which thinking, feeling and behavior follow a rigid, unhealthy pattern, deviated from the cultural norms of society.

One of the personality traits, neuroticism, appears to be correlated with a wide range of cardiovascular events, such as higher levels of blood pressure or atherosclerosis (9). Even more, the British Health and Lifestyle Survey concluded that neuroticism is associated with a higher mortality risk in coronary heart diseases (10).

An interesting report utilizing the General Practice Research Database found that risk factors for CVD occurred more frequently in psoriasis patients compared with the general population (11). Because cardiovascular disease (specifically hypertension and heart failure) and skin diseases (psoriasis) are associated with psychological changes (12), 
we hypothesize that HRQL in those patients is influenced by some characteristics of personality. The aim of this study was to investigate if personality traits may add some differences between the two groups and influence the course of the diseases.

\section{Patients and methods}

Participants. This was a cross-sectional and comparative study, performed among patients attending their scheduled follow-up visit to the psoriasis care unit and cardiovascular unit at Iași University Hospital (Iași, Romania). The present study was approved by the Clinical Research Ethics Committee of The Clinical Emergency County Hospital 'Sf. Spiridon' (Iași, Romania) and the Ethics Committee of University of Medicine and Pharmacy 'Gr. T. Popa' (Iaşi, Romania). Written informed consent was obtained from each patient prior to publication. The participation in the study was voluntary. The patients ( $\mathrm{n}=63)$ : 35 patients with psoriasis (PSO group) and 28 patients with cardiovascular diseases (CV group) were enrolled from March 2017 to December 2017; they provided their written informed consent to participate in this study. Regarding the procedure to collect data, simple random sampling technique was used to select the participants. They were informed about the purpose of the study and also that their responses will be used in a scientific study. The tests were performed in a separate room and the inclusion criteria were: a diagnosis of moderate to severe plaque-type psoriasis/hypertension or cardiac failure for at least one year and an age of over 18 years.

The exclusion criteria consisted of the diagnosis of other important diseases (neoplasia, psychiatric disorders), pregnancy, lactating women, under 18 years of age. In addition, for the PSO group, any systemic treatment and any cardiovascular diseases constituted further exclusion criteria. No patients with the inability to understand the questions in the questionnaire were included. In total, 66 patients were excluded, 44 due to exclusion criteria, 20 who refused to participate and 2 due to incomplete data from questionnaires.

Measures. The SF-36 questionnaire, developed by New England Medical Center in the Medical Outcomes Study, contains 36 items that assess the physical and mental health of the subject. This questionnaire has been used, so far, to evaluate HRQL in patients diagnosed with glaucoma, asthma, chronic obstructive bronchopneumonia, allergic rhinitis, spinal trauma, morbid obesity and psoriasis. SF-36 improves the information obtained from the questionnaires referring strictly to the medical condition and offers a wider perspective on the impact of a certain disease on the quality of life (13-16).

The Eysenck test contains questions on how the patient acts, behaves or experiences certain feelings. Thus, this test can detect the patient's ability to respond truthfully, highlighting as well his/her tendency to be introverted or extroverted. The Eysenck test was used in clinical trials that highlighted neurotic changes, but it was also used in detecting changes in personality in dermatological conditions, such as acne vulgaris, as well as in other conditions, including insomnia or coronary artery disease (17-19).
Because temperament and personality traits have both universal and regional characteristics, we have also chosen to use the questionnaire of the Profile of Emotional Distress (PED), a specific tool designed for the Romanian population (20). This questionnaire was designed to assess the subjective dimension of functional negative emotions, dysfunctional negative emotions and positive emotions. The basic idea of this model is that at the root of emotional and behavioral problems there are dysfunctional and irrational beliefs about oneself, the world and life. The scale includes 39 items and allows the calculation of a general distress score, a negative emotion score, a positive emotion score, and scores for 'worry', 'anxiety' and 'depression' (dysfunctional). In this study, we calculated the general score of distress and the score of dysfunctional negative emotions.

Statistical analysis. Data was loaded and processed using statistical functions in SPSS 18.0 (PASW statistics). The Skewness/Kurtosis test $(>-2$ P-value $<2$ ) was utilized to test the normality of the set of values used to examine a continuous variable. The ANOVA test was used to analyze the dispersion of the dependent variable, intra- and intergroup. After applying the ANOVA test, Bonferroni (post-hoc Bonferroni) correction was performed. This correction reduces the type I error rate when testing multiple hypotheses. When calculating the significant difference between two or more groups, based on the distribution of the value series, the significance threshold of $95 \%$ was applied to the quantitative tests: Student's t-test, paired samples t-test and Chi-square test. In addition, the Kruskall-Wallis test was used to compare ordinal variables from three or more groups, but it was used for specific/predictive balance plotting at the ROC curve, which served as a prognostic factor. $\mathrm{P}<0.05$ was considered to indicate a statistically significant difference.

\section{Results}

The age of the patients varied from 18 to 86 years, the mean was $53.95 \pm 16.30$ years. In both study groups there was a high educational status (31.4\% in the PSO group vs. $50 \%$ in the CV group) without significant difference $(\mathrm{P}=0.488)$. The dominant occupational status in both study groups was that of an employee (48.6\% in the PSO group vs. 57.1\% in the CV group, $\mathrm{P}=0.266$ ). ROC curve confirmed that the socio-demografic characteristics are not a predictive method of evaluating the quality diagnostic in patients with psoriasis in comparison with control group (Fig. 1).

The SF-36 values, which represent physical functions on a scale from 0 to 100 , had no significant difference in the mean scores of the study groups (42.43 in the PSO group vs. 38.04 in the $\mathrm{CV}$ group, $\mathrm{P}=0.557)$. This indicates that physical functions were reduced in both groups. In a comparative study of mean scores of SF-36, limited physical health did not reveal significant differences (56.98 in the PSO group vs. 55.16 in the $\mathrm{CV}$ group, $\mathrm{P}=0.332$ ). Approximately $43 \%$ of the patients with psoriasis and $45 \%$ of those with cardiovascular disease had limitations in daily physical function caused by their physical health status.

In comparing the mean scores of SF-36, a limitation due to emotional problems did not reveal significant differences 
Table I. Association between of the quality of life and neuroticism.

\begin{tabular}{|c|c|c|c|c|c|c|}
\hline \multirow{2}{*}{$\begin{array}{l}\text { Domain } \\
\text { SF-36 }\end{array}$} & \multicolumn{3}{|c|}{ PSO group } & \multicolumn{3}{|c|}{ CV group } \\
\hline & Emotionally stable & Neuroticism & P-value & Emotionally stable & Neuroticism & P-value \\
\hline S1. Physical functions & $33.95 \pm 28.80$ & $52.50 \pm 31.73$ & 0.079 & $39.09 \pm 33.82$ & $37.35 \pm 22.30$ & 0.871 \\
\hline $\begin{array}{l}\text { S2. Limitations due to } \\
\text { physical health }\end{array}$ & $55.07 \pm 7.66$ & $59.26 \pm 7.50$ & 0.113 & $55.05 \pm 8.12$ & $55.23 \pm 5.45$ & 0.945 \\
\hline $\begin{array}{l}\text { S3. Limitations due to } \\
\text { emotional problems }\end{array}$ & $65.79 \pm 21.85$ & $84.38 \pm 20.61$ & $0.015^{\mathrm{a}}$ & $72.73 \pm 17.12$ & $91.18 \pm 16.79$ & $0.009^{\mathrm{a}}$ \\
\hline S4. Vitality & $66.84 \pm 15.29$ & $59.38 \pm 12.89$ & 0.132 & $66.36 \pm 8.09$ & $55.29 \pm 13.28$ & $0.020^{\mathrm{a}}$ \\
\hline S5. Emotional stability & $54.21 \pm 10,04$ & $54.69 \pm 11.03$ & 0.894 & $55.91 \pm 10.20$ & $54.41 \pm 8.08$ & 0.669 \\
\hline S6. Social functions & $66.45 \pm 22.07$ & $86.72 \pm 21.15$ & $0.009^{\mathrm{a}}$ & $76.14 \pm 19.73$ & $92.65 \pm 17.15$ & $0.027^{\mathrm{a}}$ \\
\hline S7. Pain & $72.63 \pm 19.10$ & $46.88 \pm 17.78$ & $0.001^{\mathrm{a}}$ & $25.01 \pm 7.54$ & $13.48 \pm 3.27$ & 0.417 \\
\hline $\begin{array}{l}\text { S8. Perception of } \\
\text { general health status }\end{array}$ & $65.26 \pm 12.64$ & $65.00 \pm 10.95$ & 0.948 & $61.82 \pm 7.51$ & $57.65 \pm 9.70$ & 0.238 \\
\hline Total score & $71.81 \pm 3.72$ & $74.33 \pm 5.13$ & 0.101 & $72.39 \pm 4.71$ & $72.28 \pm 3.14$ & 0.939 \\
\hline Right regression model & \multicolumn{2}{|c|}{$\begin{array}{c}\mathrm{y}=0.723-0.005 \mathrm{~S} 1+0.021 \\
\mathrm{~S} 2-0.012 \mathrm{~S} 3+0.005 \\
\mathrm{~S} 4-0.010 \mathrm{~S} 5+0.008 \\
\mathrm{~S} 6-0.001 \mathrm{~S} 7+0.006 \mathrm{~S} 8\end{array}$} & 0.701 & \multicolumn{2}{|c|}{$\begin{array}{c}\mathrm{y}=-2.991+0.004 \mathrm{~S} 1+0.021 \\
\mathrm{~S} 2-0.005 \mathrm{~S} 3+0.008 \\
\mathrm{~S} 4+0.008 \mathrm{~S} 5-0.006 \\
\mathrm{~S} 6+0.008 \mathrm{~S} 7+0.049 \mathrm{~S} 8\end{array}$} & $0.011^{\mathrm{a}}$ \\
\hline
\end{tabular}

PSO, psoriasis; $\mathrm{CV}$, cardiovascular diseases. ${ }^{\mathrm{a}} \mathrm{P}<0.05$, indicates statistically significant difference.

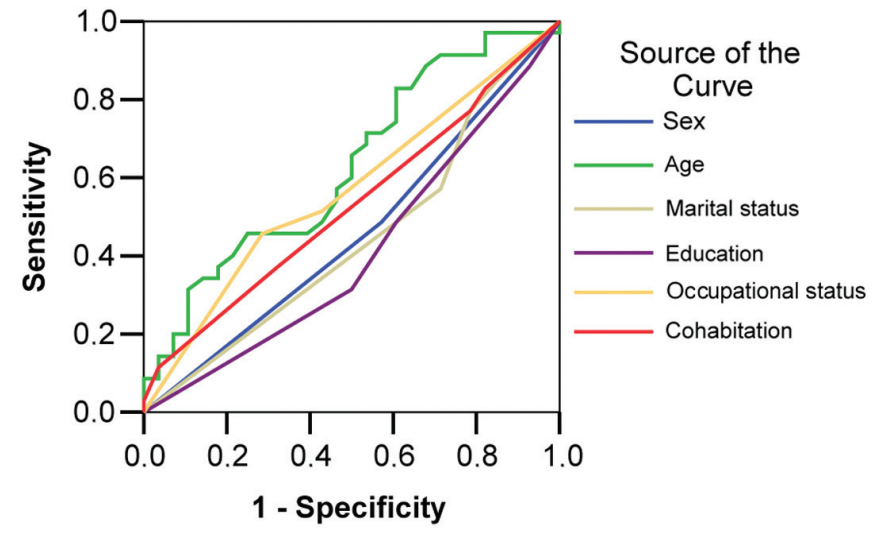

Figure 1. ROC curve in patients with psoriazis.

(74.29 in the PSO group vs. 83.93 in the $\mathrm{CV}$ group; $\mathrm{P}=0.079$ ). In approximately $25 \%$ of the patients with psoriasis and $16 \%$ of those with cardiovascular disease, emotional problems had led to limitations in physical activity.

The energy/fatigue range recorded a slightly higher average score in patients with psoriasis (63.43 in the PSO group vs. 59.64 in the $\mathrm{CV}$ group, $\mathrm{P}=0.281$ ), yet $37 \%-40 \%$ of the patients in the two study groups reported a decrease in vitality due to health problems.

In comparison, the mean scores of SF-36 show that social functions revealed significant differences (75.71 in the PSO group vs. 86.16 in the $\mathrm{CV}$ group, $\mathrm{P}=0.05$ ). In approximately $24 \%$ of the patients with psoriasis and $14 \%$ of those with cardiovascular disease, the way they perceived their health during the previous month greatly impacted social interactions.
In approximately $40 \%$ of the patients in both study groups, the pain recorded in the last 4 weeks reduced the quality of life (60.86 in the PSO group vs. 60 in the $\mathrm{CV}$ group, $\mathrm{P}=0.872$ ).

Regarding personality traits in psoriasis, for patients with an introvert personality the average scores of physical functions and limitations brought on by emotional problems were significantly higher according to the Eysenck questionnaire scores (Table I).

In cardiovascular patients with introvert personality, the mean scores of limitation domains due to emotional problems and social functions were significantly higher (Table I).

In patients with extrovert personality, the mean scores in the vitality domain and the perception of their general condition were significantly higher (Table I).

In patients with psoriasis, who were also emotionally stable, the mean pain level was significantly higher. In patients with cardiovascular disease who were also emotionally stable, the mean vitality scores were significantly higher (Table I).

P-values for Student's t-test for PSO vs. CV groups: i) $\mathrm{P}<0.001$; ii) $\mathrm{P}<0.01$ iii) $\mathrm{P}<0.05$ no significant data were collected.

In patients with psoriasis and high or very high grade of dysfunctional negative emotions, the mean scores in the physical function domain were greater (18 and 39.62 vs. 57.86 and $65 ; \mathrm{P}=0.023)$ and limitations due to emotional problems (53.33 and 67.95 vs. 90.48 and 83.33; $\mathrm{P}=0.002$ ) were significantly higher. The mean pain level was significantly higher in patients with low or average dysfunctional negative emotions (72 vs. $65.38 ; 50$ and $40 ; \mathrm{P}=0.042$ ) (Table II).

In patients with psoriasis and low or medium grade dysfunctional negative emotions, the mean scores of vitality (68 and 66.92 vs. 55.71 and $60 ; \mathrm{P}=0.035$ ) and pain 
Table II. Association between the quality of life and dysfunctional negative emotions in two study groups.

\begin{tabular}{|c|c|c|c|c|c|c|c|c|c|c|c|}
\hline \multirow{2}{*}{$\begin{array}{l}\text { Domain } \\
\text { SF-36 }\end{array}$} & \multicolumn{5}{|c|}{ PSO group } & \multicolumn{5}{|c|}{ CV group } & \multirow{2}{*}{$\begin{array}{l}\text { F ANOVA test } \\
\text { PSO vs. CV }\end{array}$} \\
\hline & Low & Medium & Higher & Very high & P-value & Low & Medium & High & Very high & P-value & \\
\hline S1 & 18.00 & 39.62 & 57.86 & 65.00 & $0.023^{\mathrm{a}}$ & 10.00 & 44.00 & 42.89 & 0.00 & $0.016^{\mathrm{a}}$ & $\mathrm{F}=0.349 \mathrm{P}=0.557$ \\
\hline S2 & 50.37 & 57.69 & 58.33 & 66.67 & 0.207 & 50.00 & 55.19 & 55.26 & 68.52 & 0.096 & $\mathrm{~F}=3.515 \mathrm{P}=0.066$ \\
\hline S3 & 53.33 & 67.95 & 90.48 & 83.33 & $0.002^{\mathrm{a}}$ & 66.67 & 80.00 & 89.47 & 50.00 & $0.046^{\mathrm{a}}$ & $\mathrm{F}=0.026 \mathrm{P}=0.872$ \\
\hline S4 & 68.00 & 66.92 & 55.71 & 60.00 & $0.035^{\mathrm{a}}$ & 63.33 & 66.00 & 56.32 & 80.00 & 0.137 & $\mathrm{~F}=3.745 \mathrm{P}=0.133$ \\
\hline S5 & 56.00 & 54.62 & 54.29 & 60.00 & 0.875 & 53.33 & 56.00 & 54.47 & 65.00 & 0.700 & $\mathrm{~F}=1.184 \mathrm{P}=0.281$ \\
\hline S6 & 57.50 & 73.08 & 86.61 & 100.0 & 0.038 & 66.67 & 82.50 & 53.68 & 80.00 & $0.030^{\mathrm{a}}$ & $\mathrm{F}=3.188 \mathrm{P}=0.079$ \\
\hline S7 & 72.00 & 65.38 & 50.00 & 40.00 & 0.042 & 83.33 & 80.00 & 66.00 & 53.68 & $0.026^{\mathrm{a}}$ & $\mathrm{F}=0.993 \mathrm{P}=0.323$ \\
\hline S8 & 78.00 & 64.62 & 62.14 & 60.00 & 0.101 & 63.33 & 64.00 & 57.89 & 50.00 & 0.334 & $\mathrm{~F}=0.054 \mathrm{P}=0.817$ \\
\hline Global score & 69.26 & 72.97 & 74.57 & 77.78 & 0.076 & 68.52 & 73.52 & 72.61 & 72.22 & 0.307 & $\mathrm{~F}=0.362 \mathrm{P}=0.550$ \\
\hline
\end{tabular}

PSO, psoriasis; $\mathrm{CV}$, cardiovascular diseases. ${ }^{\mathrm{a}} \mathrm{P}<0.05$, indicates statistically significant difference.

Table III. Association between dysfunctional negative emotions and PED scores (introversion, extroversion, neuroticism).

\begin{tabular}{|c|c|c|c|c|c|c|c|c|c|}
\hline \multirow[b]{3}{*}{ PDA } & \multicolumn{8}{|c|}{ Dysfunctional negative emotions } & \multirow{3}{*}{$\begin{array}{c}\text { P-values for } \\
\text { Kruskal-Wallis } \\
\text { test } \\
\text { PSO vs. CV }\end{array}$} \\
\hline & \multicolumn{4}{|c|}{ PSO group } & \multicolumn{4}{|c|}{ CV group } & \\
\hline & $\begin{array}{l}\text { Low } \\
(\%)\end{array}$ & $\begin{array}{l}\text { Medium } \\
\text { (\%) }\end{array}$ & $\begin{array}{l}\text { High } \\
(\%)\end{array}$ & $\begin{array}{c}\text { Very high } \\
(\%)\end{array}$ & $\begin{array}{l}\text { Low } \\
(\%)\end{array}$ & $\begin{array}{l}\text { Medium } \\
(\%)\end{array}$ & $\begin{array}{l}\text { High } \\
(\%)\end{array}$ & $\begin{array}{l}\text { Very high } \\
(\%)\end{array}$ & \\
\hline Introversion & 80.0 & 15.4 & 71.4 & 100.0 & 0.0 & 0.0 & 52.6 & 0.0 & $0.001^{\mathrm{b}}$ \\
\hline Ambivert & 20.0 & 76.9 & 21.4 & 0.0 & 100.0 & 60.0 & 47.4 & 100.0 & $0.001^{\mathrm{b}}$ \\
\hline Extroversion & 0.0 & 7.7 & 7.1 & 0.0 & 0.0 & 40.0 & 0.0 & 0.0 & 0.423 \\
\hline P-value & \multicolumn{4}{|c|}{$0.023^{\mathrm{b}}$} & \multicolumn{4}{|c|}{$0.014^{\mathrm{b}}$} & \\
\hline Emotionally stable & 100.0 & 53.8 & 35.7 & 0.0 & 66.7 & 80.0 & 26.3 & 0.0 & 0.713 \\
\hline Neuroticism & 0.0 & 46.2 & 64.3 & 100.0 & 33.3 & 20.0 & 73.7 & 100.0 & 0.075 \\
\hline P-value ${ }^{a}$ & \multicolumn{4}{|c|}{$0.005^{\mathrm{b}}$} & \multicolumn{4}{|c|}{$0.031^{\mathrm{b}}$} & \\
\hline
\end{tabular}

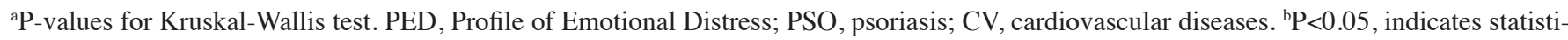
cally significant difference.

(72 and 65.38 vs. 50 and 40; $\mathrm{P}=0.042$ ) were significantly higher (Table II).

In patients with cardiovascular problems, the following statistically significant differences in mean values of SF-36 scores were noted, in terms of dysfunctional negative emotions: physical functions associated with an average emotional level (10 and 44 vs. 42.9 and 42.89; $\mathrm{P}=0.016$ ), limitations due to emotional problems associated with a level of medium-high dysfunctional negative emotions (66.67 and 80 vs. 89.47 and 50; $\mathrm{P}=0.046$ ), social functions associated with an average or high emotional level (66.67 and 82.50 vs. 53.68 and $80 ; \mathrm{P}=0.039$ ) and pain associated with a level of low dysfunctional negative emotions toward the environment (83.33 and 80 vs. 66 and 63.68; $\mathrm{P}=0.026$ ) (Table II).

In patients with psoriasis, introversion and neuroticism have been associated with a high $(71.4 \%)$ and very high level $(100 \%)$ of dysfunctional negative emotions $(\mathrm{P}=0.023)$ (Table III).
Of the patients with psoriasis $59.1 \%$ had high levels of distress presenting neurotic features.

Eysenck test. The ability to manipulate responses was noted in $31.7 \%$ of the subjects, slightly more frequent in the group of patients with psoriasis (40\% PSO group vs. $21.4 \% \mathrm{CV}$ group, $\mathrm{P}=0.272$ ) and there was no significant sex difference in the study groups who were inclined to lie or conceal the truth.

Approximately $60 \%$ of single patients with psoriasis have the ability to manipulate the responses while $75 \%$ of patients with cardiovascular disease have reserved responses $(\mathrm{P}=0.05)$. Comparing the two study groups, the responses marked in the lie domain are not significantly associated with educational status.

Furthermore, $40 \%$ of single patients with psoriasis and $50 \%$ of patients with cardiovascular diseases were introvert, $85.4 \%$ of widowed patients with psoriasis and $50 \%$ of cardiovascular 
patients were introvert and no extravert personality types were noted among widowed patients $(\mathrm{P}=0.312)$.

Neuroticism was noted in $52.4 \%$ of the subjects, slightly more frequent in the group of patients with cardiovascular disease $(60.7 \%$ in the CV group vs. $45.7 \%$ in the PED group, $\mathrm{P}=0.235$ ). Moreover, all patients with elementary education, no matter which study group they were a part of, presented elements of neuroticism.

\section{Affective distress profile.}

Sadness/depression. Functional PDA scores ranged from 6 to 28, registering a slightly higher average in patients with cardiovascular disease (16.07 in the CV group vs. 13.60 in the PSO group, $\mathrm{P}=0.057)$, while the functional PDA score varied from 8 to 31, registering a significantly higher mean in patients with cardiovascular disease (17.86 in the $\mathrm{CV}$ group vs. 14.40 in the PSO group, $\mathrm{P}=0.024)$.

Concern/Anxiety. Functional PDA score ranged from 8 to 28 , recording a significantly higher mean in patients with cardiovascular disease (19.04 in the CV group vs. 15.80 in the PSO group, $\mathrm{P}=0.016$ ) and the functional PDA score ranged from 6 to 36, also registering a significantly higher mean in patients with cardiovascular disease (14.0 in the CV group vs. 11.60 in the PSO group, $\mathrm{P}=0.039$ ).

Patients with psoriasis are experiencing less dysfunctional emotions than patients with cardiovascular disease. This is associated with a higher level of distress experienced by patients with cardiovascular disease compared to patients with psoriasis, as shown by the results below:

i) Functional negative emotions: In the psoriasis group, $37.1 \%$ of the patients had an average level of functional negative emotions and $37.2 \%$ were high and very high, while in the group with cardiovascular disease, $60.7 \%$ of patients had high and very high levels of functional negative emotions $(\mathrm{P}=0.011)$ and ii) dysfunctional negative emotions: In the psoriasis group, $40 \%$ of the patients had a high level of dysfunctional negative emotions and $37.1 \%$ had a medium level of dysfunctional negative emotions, while in the group with cardiovascular disease, $67.9 \%$ of the patients had a high level of dysfunctional negative emotions $(\mathrm{P}=0.045)$.

Positive emotions. The PDA score for positive emotions ranged from 19 to 58, showing a slightly higher average in patients with psoriasis (37.66 in the PSO group vs. 36.43 in the $\mathrm{CV}$ group, $\mathrm{P}=0.615)$.

Total PDA. The total PDA score ranged from 61 to 139 , with a significantly higher mean in cardiovascular patients (103.39 in the CV group vs. 93.06 in the PSO group, $\mathrm{P}=0.008$ ).

The overall PDA score in $73 \%$ of patients was very high with a significantly higher percentage in patients with cardiovascular disease $(85.7 \%$ in the $\mathrm{CV}$ group vs. $62.9 \%$ in the PSO group, $\mathrm{P}=0.039)$.

\section{Discussion}

The main findings of the present study are: i) Regarding personality traits, neuroticism was present in all patients with elementary education, regardless of the study group they were in and anxiety was associated with a low level of education as well and ii) regarding HRQL, in the PSO group, we noted a greater impact of diagnosis on social interactions. In approximately $40 \%$ of the patients in both study groups, pain recorded in the last 4 weeks reduced the quality of life and daily physical functions were reduced by physical health in approximately $40 \%$ in both groups.

The role of stress in modulation of skin inflammation, the quality of life in patients with psoriasis and the psychological changes associated with this condition have been extensively studied and the results have shown differences in ethnicity, sex or other stress factors (smoking) (21-23). The severity of the disease or its duration is not of the utmost importance, but rather the social impact of the lesions. If the lesions are located in visible areas, they have a greater effect on the quality of life of the patient, even if their size is small $(24,25)$. Most studies used an HRQL assessment method in psoriasis patients with the Dermatology Quality of Life Index (DLQI) questionnaire in association with the Psoriasis Area Severity Index (26-28). However, it has been observed that there is no direct link to the severity of lesional extension, which is mainly assessed by PASI and the degree of psychological impairment of the patient (25). The correlation of PASI with HRQL differs greatly depending on the patient's temperament (29).

Emotion regulation is a process by which emotions are modulated both consciously and unconsciously (30) and depression is frequently considered a disorder that occurs because of a dysfunction of emotion regulation strategies (31). Our results show that patients with psoriasis experience a lower degree of dysfunctional emotions than patients with cardiovascular disease. It could be interpreted as an association with a higher level of distress experienced by patients with cardiovascular disease in a strict relation with their disease.

These ideas highlight the fact that the psychic component plays a much more important role than previously thought and its importance should be reevaluated; our results support this idea. In our case, the patient's health in the month prior to assessment prevented social engagement. Furthermore, in approximately $40 \%$ of the patients in both study groups, pain reduced quality of life over the last 4 weeks.

Patients with psoriasis and introverted personality tend to limit physical activity and are more emotionally vulnerable, which may exacerbate the effects of the disease and therapeutic compliance or even aggravation of the symptoms. It is precisely because of the patient's personality structure, quality of life and emotional stability that there is a need for additional psychological support in these patients.

Our result revealed elements of neuroticism in all patients with psoriasis who had elementary studies, while in those with higher education only $45.5 \%$ presented high scores on neuroticism. We found that anxiety was associated with a low level of education and similar conclusions have also been drawn in studies from other countries (32).

We can consider that emotional instability may constitute a personality trait and is common for both patients with psoriasis and patients with cardiovascular disease; a personality trait that is found in personality type A, but also personality type D.

We believe that it is necessary to include items evaluating the patients' affective profile in the assessment protocols of these diseases, since that could help the clinician in identifying possible factors that signal worsening of the disease or of non-response to treatment. 
This study used three different tests, which made comparing the results more difficult. Since testing has only been done once, the perception of quality of life, affective perception of the patient may change over the course of the disease and the treatment. Last, but not least, self-administered testing can influence the test results due to the desire to impress the tester or other patients. Considering that psoriasis is a chronic condition accompanied by exacerbations and remissions, it is also necessary to evaluate patients at the time of maximum symptoms.

In conclusion, the present study shows interesting relations between personality traits, such as emotion instability or neuroticism, and physical problems; also in addition, it shows an association between these diseases and the quality of life.

\section{Acknowledgements}

The authors are grateful to Radu Iliescu, the senior scientist who made valuable suggestions for improvements to the manuscript. Professional editing, linguistic and technical assistance performed by Individual Service Provider Irina Radu, certified translator in Medicine and Pharmacy.

\section{Funding}

Article in the project 'Cardiovascular risk assessment protocol in patients with psoriasis' (PSOCARDIO), funded by Romanian Society of Dermatology and Venereology.

\section{Availability of data and materials}

All data and materials supporting the results of the present study are available in the published article.

\section{Authors' contributions}

All authors contributed to the acquisition of the data and critical revision of manuscript for important intellectual content. EPA, LGS were responsible for the research design, manuscript drafting, analysis and interpretation of data. DV was responsible for language editing and RP for interpretation of the questionnaires. LS, CS, AIG, AIP, IAP have shared questionnaires and statically processed the results. DV contributed to the data analysis and the critical interpretation. LGS has critically reviewed the manuscript. All authors read and approved the final version of the manuscript.

\section{Ethics approval and consent to participate}

The present study was approved by the Clinical Research Ethics Committee of The Clinical Emergency County Hospital 'Sf. Spiridon' (Iași, Romania) and the Ethics Committee of University of Medicine and Pharmacy 'Gr. T. Popa' (Iași, Romania). Written informed consent was obtained from each patient prior to publication.

\section{Patient consent for publication}

Not applicable.

\section{Competing interests}

The authors declare that they have no competing interests.

\section{References}

1. Lowe JG: The stigma of acne. Br J Hosp Med 49: 809-812, 1993.

2. Kouris A, Platsidaki E, Christodoulou C, Armyra K, Korkoliakou P, Stefanaki C, Tsatovidou R, Rigopoulos D and Kontochristopoulos G: Quality of life, depression, anxiety and loneliness in patients with bullous pemphigoid. A case control study. An Bras Dermatol 91: 601-603, 2016.

3. Solomon I, Ilie MA, Draghici C, Voiculescu VM, Căruntu C, Boda D and Zurac S: The impact of lifestyle factors on evolution of atopic dermatitis: An alternative approach. Exp Ther Med 17: 1078-1084, 2019.

4. Caruntu C, Boda D, Constantin C, Caruntu A and Neagu M: Catecholamines increase in vitro proliferation of murine B16F10 melanoma cells. Acta Endo 10: 545-558, 2014.

5. Căruntu C, Boda D, Musat S, Căruntu A and Mandache E: Stress-induced mast cell activation in glabrous and hairy skin. Mediators Inflamm 2014: 105950, 2014.

6. Caruntu C, Boda D, Musat S, Caruntu A, Poenaru E, Calenic B, Savulescu-Fiedler I and Draghia A: Rotaru M and Badarau AI: Stress effects on cutaneous nociceptive nerve fibers and their neurons of origin in rats. Rom Biotechnol Lett 19: 9517-9530, 2014.

7. Boda D, Negrei C, Nicolescu F and Balalau C: Assessment of some oxidative stress parameters in methotrexate treated psoriasis patients. Farmacia 62: 704-710, 2014.

8. Jafferany M and Franca K: Psychodermatology: Basics concepts. Acta Derm Venereol 96: 35-37, 2016.

9. Jylhä P and Isometsä E: The relationship of neuroticism and extraversion to symptoms of anxiety and depression in the general population. Depress Anxiety 23: 281-289, 2006.

10. Shipley BA, Weiss A, Der G, Taylor MD and Deary IJ: Neuroticism, extraversion, and mortality in the UK Health and Lifestyle Survey: A 21-year prospective cohort study. Psychosom Med 69: 923-931, 2007.

11. Kaye JA, Li L and Jick SS: Incidence of risk factors for myocardial infarction and other vascular diseases in patients with psoriasis. Br J Dermatol 159: 895-902, 2008.

12. Goyal A, Dey AK, Chaturvedi A, Elnabawi YA, Aberra TM, Chung JH, Belur AD, Groenendyk JW, Lerman JB, Rivers JP et al: Chronic stress-related neural activity associates with subclinical cardiovascular disease in psoriasis: A prospective cohort study. JACC Cardiovasc Imaging: Noe 15, 2018 (Epub ahead of print).

13. Unalan H, Gençosmanoğlu B, Akgün K, Karamehmetoğlu S, Tuna H, Ones K, Rahimpenah A, Uzun E and Tüzün F: Quality of life of primary caregivers of spinal cord injury survivors living in the community: Controlled study with short form-36 questionnaire. Spinal Cord 39: 318-322, 2001.

14. Doll HA, Petersen SEK and Stewart-Brown SL: Obesity and physical and emotional well-being: Associations between body mass index, chronic illness, and the physical and mental components of the SF-36 questionnaire. Obes Res 8: 160-170, 2000 .

15. Leynaert B, Neukirch C, Liard R, Bousquet J and Neukirch F: Quality of life in allergic rhinitis and asthma. A population-based study of young adults. Am J Respir Crit Care Med 162: 1391-1396, 2000.

16. Sampogna F, Tabolli S, Söderfeldt B, Axtelius B, Aparo U and Abeni D; IDI Multipurpose Psoriasis Research on Vital Experiences (IMPROVE) investigators: Measuring quality of life of patients with different clinical types of psoriasis using the SF-36. Br J Dermatol 154: 844-849, 2006.

17. Gül Aİ and Çölgeçen E: Personality traits and common psychiatric conditions in adult patients with acne vulgaris. Ann Dermatol 27: 48-52, 2015.

18. Bayar N, Güven R, Erkal Z, Akyol KC, Edebali MI, Küçükseymen S and Arslan Ş: Assessment of the association between the personality traits of young patients with acute coronary syndrome and the severity of coronary artery disease. Turk Kardiyol Dern Ars 45: 514-519, 2017.

19. Liao J,Zhu S, Zhang Q, Wang D and Li X: Personal characteristics of paradoxical insomnia: A case-control study. Zhong Nan Da Xue Xue Bao Yi Xue Ban 42: 958-965, 2017 (In Chinese). 
20. Opris D and Macavei B: The profile of emotional distress norms for the Romanian population. J Cogn Behav Psychother 7: 139-157, 2007.

21. Căruntu C, Boda D, Căruntu A, Rotaru M, Baderca F and Zurac S: In vivo imaging techniques for psoriatic lesions. Rom J Morphol Embryol 55 (Suppl): 1191-1196, 2014.

22. Grigore O, Mihailescu AI, Solomon I, Boda D and Caruntu C: Role of stress in modulation of skin neurogenic inflammation. Exp Ther Med 17: 997-1003, 2019.

23. Ilie MA, Caruntu C, Lixandru D, Tampa M, Georgescu SR, Constantin MM, Constantin C, Neagu M, Zurac SA and Boda D: In vivo confocal laser scanning microscopy imaging of skin inflammation: Clinical applications and research directions. Exp Ther Med 17: 1004-1011, 2019.

24. Çakmur H and Derviş E: The relationship between quality of life and the severity of psoriasis in Turkey. Eur J Dermatol 25: $169-176,2015$

25. Yang HJ and Yang KC: Impact of psoriasis on quality of life in Taiwan. Zhonghua Pifuke Yixue Zazhi 33: 146-150, 2015 (In Chinese).

26. Basra MK, Fenech R, Gatt RM, Salek MS and Finlay AY: The Dermatology Life Quality Index 1994-2007: A comprehensive review of validation data and clinical results. Br J Dermatol 159 : 997-1035, 2008.

27. Revicki DA, Willian MK, Menter A, Saurat JH, Harnam N and Kaul M: Relationship between clinical response to therapy and health-related quality of life outcomes in patients with moderate to severe plaque psoriasis. Dermatology 216: 260-270, 2008.
28. Olteanu R, Constantin MM,Zota A, Dorobantu DM, Constantin T, Șerban ED, Bălănescu P, Mihele D and Gheucă Solovăstru L: Original clinical experience and approach to treatment study with interleukine 12/23 inhibitor in moderate-to-severe psoriasis patients. Farmacia 64: 2-5, 2016

29. Janowski K and Steuden S: Severity of psoriasis and health-related quality of life: The moderating effects of temperament. Br J Dermatol 158: 633-635, 2008

30. Bargh JA and Williams LE: On the non conscious of emotion regulation. Gross JJ. (Ed.), Handbook of Emotion Regulation, Guilford Press. New York, pp429-444, 2007.

31. Mennin DS, Holaway RM, Fresco DM, Moore MT and Heimberg RG: Delineating components of emotion and its dysregulation in anxiety and mood psychopathology. Behav Ther 38: 284-302, 2007.

32. Sidlauskaitè-Stripeikienè I, Zemaitienè N and Klumbienè J: Associations between depressiveness and psychosocial factors in Lithuanian rural population. Medicina (Kaunas) 46: 693-699, 2010 .

This work is licensed under a Creative Commons Attribution-NonCommercial-NoDerivatives 4.0 International (CC BY-NC-ND 4.0) License. 